\title{
Role of Potassium and Calcium on the Combustion Characteristics of 2 Biomass Obtained from Thermogravimetric Experiments
}

\author{
${ }_{3}$ M. Abián, ${ }^{* \dagger \odot}$ M. U. Alzueta, ${ }^{\dagger}$ A. Carvalho, ${ }^{\ddagger}$ M. Rabaçal, ${ }^{\ddagger}$ and M. Costa ${ }^{\ddagger}$ \\ $4{ }^{\dagger}$ Aragón Institute of Engineering Research (I3A), Department of Chemical and Environmental Engineering, University of Zaragoza, \\ 550018 Zaragoza, Spain \\ $6{ }^{\ddagger}$ Institute of Mechanical Engineering (IDMEC), Mechanical Engineering Department, Instituto Superior Técnico, Universidade de \\ 7 Lisboa, 1049-001 Lisboa, Portugal
}

8 S Supporting Information

9 ABSTRACT: This work focuses on the combustion behavior of raw and demineralized grape pomace and grape pomace doped

10 with $0.1,0.5,0.82$ (equal to the $\mathrm{K}$ concentration in the raw biomass), 3 , and 6 wt $\% \mathrm{~K}$ and $0.1,0.5,1.08$ (equal to the Ca

11 concentration in the raw biomass), 3, and $6 \mathrm{wt} \% \mathrm{Ca}$. To identify the individual role of calcium and potassium, the biomass

12 samples were either pyrolyzed in a $\mathrm{N}_{2}$ atmosphere or oxidized in air in a thermogravimetric analyzer (TGA) during non-

13 isothermal runs at $10 \mathrm{~K} / \mathrm{min}$ from room temperature to a maximum temperature of $1275 \mathrm{~K}$. In all of the cases, the biomass

14 pyrolysis process shows one main stage associated with the volatile matter release. This process is not significantly affected by the

15 mineral content of biomass nor the presence of high $\mathrm{K}$ and $\mathrm{Ca}$ contents. During combustion in air, the biomass samples show

16 two main distinct stages that are associated with the volatile matter release and the char oxidation. Whereas the main

17 devolatilization stage is not significantly affected by the mineral content of the biomass, the char oxidation stage is shifted to

18 higher temperatures for the demineralized biomass. Potassium and calcium play a different role on the char oxidation process. In

19 general, char oxidation is promoted with increasing the K content, whereas Ca does not significantly influences this process. The

20 TGA results were also used to determine the kinetic parameters of the pyrolysis and combustion processes of biomass in the

21 presence of $\mathrm{K}$ and $\mathrm{Ca}$.

\section{INTRODUCTION}

22 The use of biomass in combustion has increased over the last 23 few decades because it is considered as a renewable and $\mathrm{CO}_{2}$ 24 neutral energy source. However, despite the growing develop25 ment of different technologies for the thermochemical 26 conversion of biomass, there are still issues, such as preparation 27 of biomass and/or ash-related matters during and after 28 combustion, that hinder the clean and efficient utilization of 29 biomass in energy applications. ${ }^{1}$ In particular, the presence of 30 metals, even in small quantities, may affect the overall 31 combustion process and the formation of pollutants. ${ }^{2}$

32 The pyrolysis of solid fuels produces volatiles and char, 33 which, in turn, result from both the direct primary 34 decomposition of the solid fuel and the secondary reactions 35 of volatile condensable organic products. ${ }^{3}$ During combustion, 36 the decomposition of the organic structures of biomass is 37 accompanied by the release of its mineral constituents. Once 38 released, the metals can be transported in the combustion gas 39 as either solid particles or vapor species, ${ }^{1}$ depending upon the 40 given element considered. Although the mineral content 41 depends upon the type of biomass (e.g., refs 4 and 5), 42 potassium $(\mathrm{K})$ is typically the main alkali earth metal and 43 calcium ( $\mathrm{Ca}$ ) is the main alkaline metal present in biomass. ${ }^{6}$ 44 Usually, $\mathrm{K}$ is regarded as an undesirable biomass component as 45 a result of its critical role in important ash-related problems 46 (e.g., alkali-induced slagging, silicate melt-induced slagging, ash 47 fusion, and bed agglomeration). ${ }^{1,7}$ In contrast and despite the 48 calcium sulfate deposits found on the cold reactor surfaces, $\mathrm{Ca}$ 49 can inhibit the occurrence of silicate melt-induced slagging and bed agglomeration as a result of the formation of melting 50 calcium potassium phosphates and silicates at high temper- 51 atures. $^{1,8,9}$

$\mathrm{K}$ is mostly present in biomass in a soluble form (e.g., in an 53 ionic form in salts or as organically bound $\mathrm{K}$ ions). ${ }^{1}$ Two 54 characteristic temperature intervals have been identified for the 55 release of $\mathrm{K}$, as alkali metal, during biomass pyrolysis. ${ }^{10} \mathrm{~K} 56$ associated with the organic phase is expected to be released 57 coinciding with the onset of the pyrolysis process (453-773 58 $\mathrm{K}$ ), whereas inorganic $\mathrm{K}$, from the ash component of the 59 resulting char, would be released at higher temperatures (>773 60 K).

During combustion, soluble $\mathrm{K}$ is mainly released to the gas 62 phase as $\mathrm{K}(\mathrm{g}), \mathrm{KOH}(\mathrm{g})$, and $\mathrm{KCl}(\mathrm{g})$ provided that $\mathrm{Cl}$ is 63 available. Subsequently, these $\mathrm{K}$ species can interact with other 64 compounds through different reactions depending upon the 65 given reaction environment. In the absence of chlorine and 66 sulfur, possible reactions include the interaction of $\mathrm{K}(\mathrm{g})$ with 67 water vapor to form $\mathrm{KOH}(\mathrm{g})$ and the subsequent carbonation 68 of hydroxide at temperatures below $1073 \mathrm{~K}^{11}$

$$
2 \mathrm{KOH}+\mathrm{CO}_{2} \leftrightarrow \mathrm{K}_{2} \mathrm{CO}_{3}+\mathrm{H}_{2} \mathrm{O}
$$

At high enough temperatures (i.e., $1180 \mathrm{~K}$ ), potassium 71 carbonate can decompose through reaction $\mathrm{R} 2 .^{12}$

Received: July 24, 2017

Revised: September 27, 2017

Published: September 28, 2017 
${ }_{73} \mathrm{~K}_{2} \mathrm{CO}_{3} \leftrightarrow \mathrm{K}_{2} \mathrm{O}+\mathrm{CO}_{2}$

74 The presence of $\mathrm{K}$ during biomass conversion in the form of 75 either $\mathrm{KOH}_{1}{ }^{13} \mathrm{~K}_{2} \mathrm{CO}_{3}{ }^{14}$ potassium acetate, ${ }^{15}$ or potassium 76 carboxylates ${ }^{16}$ promotes the char formation.

77 In addition, $\mathrm{K}$ can also act as a catalyst for the devolatilization 78 and char combustion stages of biomass. ${ }^{10,17-20}$

79 Ca can be found in biomass in three forms: organically 80 bound, acid soluble, and acid insoluble. Under combustion 81 conditions, acid-insoluble $\mathrm{Ca}$ (e.g., Ca silicates) is usually 82 considered inert, whereas organically bound and acid-soluble $83 \mathrm{Ca}$ are readily converted into $\mathrm{CaO} .{ }^{1}$ Within the combustion 84 chamber, $\mathrm{CaO}$ exists as refractory small micrometer-sized 85 particles and will stay as is provided that it is not participating 86 in further reactions. ${ }^{21}$ In general, literature works point to a 87 negligible influence of $\mathrm{Ca}$ on the main pyrolysis products of 88 biomass. ${ }^{22,23}$ However, the addition of $\mathrm{Ca}$ as either $\mathrm{CaCO}_{3}{ }^{24,25}$ 89 or $\mathrm{CaO}^{25,26}$ can increase the char combustion rate.

90 Even though $\mathrm{K}$ and $\mathrm{Ca}$ can catalyze the biomass conversion 91 during both pyrolysis and combustion processes, ${ }^{18}$ the relative 92 magnitude of the effect depends upon the given metal. In this 93 way, previous studies highlight the higher catalytic activity of $\mathrm{K}$ 94 compared to $\mathrm{Ca}^{27}$

95 In this context, the aim of this work is to investigate the 96 impact of the presence and concentration of $\mathrm{K}$ and $\mathrm{Ca}$ on the 97 devolatilization and char oxidation characteristics of biomass 98 fuels, taking as a reference point grape pomace biomass. The 99 reference biomass was demineralized and subsequently doped 100 with different concentrations of $\mathrm{K}$ (using potassium oxalate 101 monohydrate as a reactant) and $\mathrm{Ca}$ (using calcium oxalate 102 monohydrate as a reactant), making a total of 12 different 103 samples. Both pyrolysis and combustion behaviors have been 104 examined in a thermogravimetric analyzer (TGA), and the 105 effects of the presence of the minerals on the sample reactivity 106 was analyzed. To this end, the characteristic temperatures of the 107 initial stage, the peak rate, and the final stage were compared 108 for the different biomass samples for both conversion processes. 109 Additionally, the minimum ignition temperature was estimated 110 using three different graphical methods. Finally, the activation 111 energies of the pyrolysis process and the devolatilization and 112 char oxidation stages in the case of combustion were estimated 113 using an optimization procedure.

\section{MATERIALS AND METHODS}

114 2.1. Sample Preparation. In this study, grape pomace biomass 115 has been selected as the reference biomass. Grape pomace is a residue 116 generated during the wine production, and it is mainly constituted by 117 skins and seeds. Table 1 lists the main properties of the grape pomace 118 biomass, and Figure 1 provides its particle size distribution.

119 To prepare the different samples, the raw grape pomace was first 120 demineralized by a nitric-acid-leaching procedure. ${ }^{28}$ In particular, $30 \mathrm{~g}$ 121 of raw biomass was placed in a flask with $500 \mathrm{~mL}$ of ion-exchanged 122 water. $\mathrm{pH}$ of the dissolution was adjusted to 2 using $\mathrm{HNO}_{3}$ and stirred 123 for $1 \mathrm{~h}$ at $60{ }^{\circ} \mathrm{C}$. Subsequently, the biomass was filtered and washed 124 thoroughly with $200 \mathrm{~mL}$ of ion-exchanged water. The filtering125 washing procedure was repeated 4 times. Finally, the biomass was 126 dried at $105{ }^{\circ} \mathrm{C}$. The complete procedure was repeated twice.

127 Afterward, the demineralized biomass was impregnated with 128 different concentrations of either $\mathrm{K}$ (using potassium oxalate 129 monohydrate as a reactant) or Ca (using calcium oxalate monohydrate 130 as a reactant). The wet impregnation procedure consists of adding 131 different amounts of $\mathrm{K}$ or $\mathrm{Ca}$ reactant to ion-exchange water to obtain 132 the desired concentrations of $\mathrm{K}$ or $\mathrm{Ca}$ in the dissolutions. 133 Subsequently, $11 \mathrm{~mL}$ of each dissolution was mixed with $5 \mathrm{~g}$ of
Table 1. Properties of the Raw Grape Pomace Biomass

\begin{tabular}{lr}
\multicolumn{1}{c}{ parameter } & value \\
\multicolumn{2}{c}{ Proximate Analysis (wt \%, As Received) } \\
volatiles & 48.4 \\
fixed carbon & 18.6 \\
moisture & 30.2 \\
ash & 2.8 \\
Ultimate Analysis (wt \%, Dry and Ash-Free & Basis) \\
carbon & 51.1 \\
hydrogen & 6.7 \\
nitrogen & 1.9 \\
sulfur & 0.2 \\
oxygen & 40.1 \\
& \\
high & Heating Value (MJ/kg) \\
low & 21.2 \\
& 19.8 \\
$\mathrm{SiO}_{2}$ & \\
$\mathrm{Al}_{2} \mathrm{O}_{3}$ & 5.5 \\
$\mathrm{Fe}_{2} \mathrm{O}_{3}$ & 1.0 \\
$\mathrm{CaO}^{2}$ & 1.2 \\
$\mathrm{SO}_{3}$ & 37.8 \\
$\mathrm{MgO}^{\mathrm{P}_{2} \mathrm{O}_{5}}$ & 1.7 \\
$\mathrm{~K}_{2} \mathrm{O}$ & 7.2 \\
$\mathrm{Na}_{2} \mathrm{O}$ & 19.7 \\
other oxides & 24.7 \\
& 0.4 \\
& 0.8
\end{tabular}

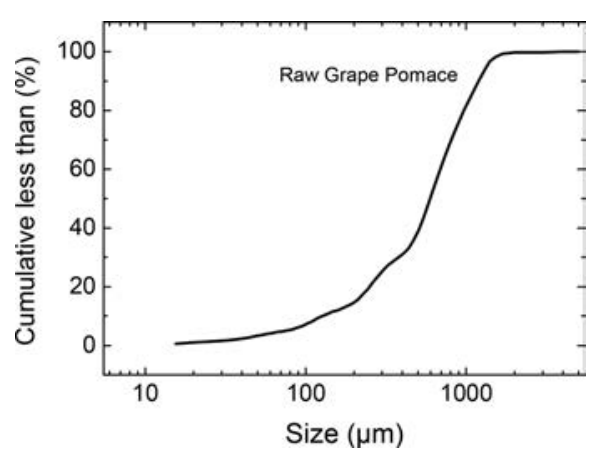

Figure 1. Particle size distribution of the raw grape pomace.

demineralized biomass. The resultant impregnated biomass samples 134 were dried at $105{ }^{\circ} \mathrm{C}$ and stored at ambient conditions.

The specific $\mathrm{K}$ and $\mathrm{Ca}$ reactant amounts were selected to cover a 136 wide and realistic range of $\mathrm{K}$ and $\mathrm{Ca}$ concentrations in different 137 biomass residues (see the work of Tortosa-Masia et al. ${ }^{4}$ ). Thus, the 138 present work includes the analysis of the pyrolysis and oxidation 139 behaviors of raw and demineralized grape pomace and grape pomace 140 doped with $0.1,0.5,0.82$ (equal to the $\mathrm{K}$ concentration in the raw 141 biomass), 3, and 6 wt $\% \mathrm{~K}$ and $0.1,0.5,1.08$ (equal to the Ca 142 concentration in the raw biomass), 3 , and 6 wt \% Ca.

2.2. Thermogravimetric Tests. The evaluation of the combustion 144 behavior of biomass is based on the measurement of the mass change 145 in a sample as a function of the temperature and time at a constant 146 heating rate of $10 \mathrm{~K} / \mathrm{min}$ from room temperature up to $1275 \mathrm{~K}$ in 147 either nitrogen or air, using a NETZSCH STA F1 Jupiter TGA. The 148 experiments were performed at atmospheric pressure using alumina 149 crucibles and $5 \mathrm{mg}$ of each biomass sample. The initial sample mass 150 and heating rate used in these tests were chosen based on previous 151 studies addressing the pyrolysis and combustion behaviors of different 152 biomass residues in TGA experiments. ${ }^{29,30}$ Prior to the experiments, 153 for each experimental condition (i.e., air or $\mathrm{N}_{2}$ atmosphere), a 154 
155 calibration curve was made to avoid possible fluctuations caused by the 156 apparatus that could influence the measurements.

157 The figures show the biomass pyrolysis and combustion reactivities 158 as the mass loss rate, $\mathrm{d} X / \mathrm{d} t\left(\mathrm{~min}^{-1}\right)$, defined through eq 1 , versus the 159 reaction temperature, $T(\mathrm{~K})$

160

$$
\frac{\mathrm{d} X}{\mathrm{~d} t}=\frac{1}{m_{0}} \frac{\mathrm{d} m}{\mathrm{~d} t}
$$

161 Here, $m_{0}$ and $m$ are the initial mass of biomass and the mass of 162 biomass at time $t$ in the TGA tests, respectively. Thus, the biomass 163 conversion, $X$, is defined by

$$
164 \quad X=\frac{m_{0}-m}{m_{0}}
$$

165 To determine the uncertainty in the experimental procedure, the 166 experiments were repeated at least 3 times. In addition, to disregard 167 the possible influence of the biomass size distribution on the TGA 168 results, the samples were sieved into the $200-250 \mu \mathrm{m}$ size interval 169 and, subsequently, subjected to the pyrolysis and combustion tests. As 170 an example of the comparison results obtained, Figure 2 shows the

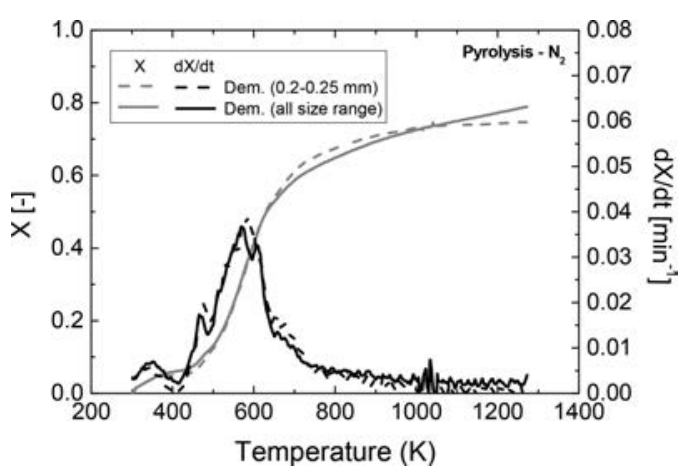

Figure 2. Typical pyrolysis profiles of the demineralized grape pomace.

171 conversion $X$ and the rate of mass loss $\mathrm{d} X / \mathrm{d} t$ for the pyrolysis of the 172 demineralized biomass. The similitude of results is high, indicating a 173 good repeatability of the procedure and a low effect of the biomass size 174 distribution of the samples under the conditions of the present work. 175 2.3. Pyrolysis and Combustion Modeling. The TGA results 176 were used to determine the kinetic parameters of the pyrolysis and 177 combustion processes of biomass in the presence of $\mathrm{K}$ and Ca. This 178 analysis was carried out using the fitting procedure developed by 179 Ferreiro et al. ${ }^{30}$ The method includes a combined genetic algorithm 180 from the global optimization toolbox of MATLAB and the least 181 squares (LSQ) fitting procedure of MATLAB for the estimation of the 182 activation energy and pre-exponential factor of both pyrolysis and 183 combustion of biomass through the use of a single first-order reaction 184 model. A detailed description of the procedure can be found 185 elsewhere. $^{30}$

186 Both pyrolysis and devolatilization are modeled using a single first187 order reaction. ${ }^{3}$ The reaction rate is defined as a function of the 188 temperature and degree of conversion through eq 3

$$
189 \quad \frac{\mathrm{d} m}{\mathrm{~d} t}=k\left(T_{\mathrm{p}}\right)\left(V M-V_{\mathrm{g}}\right)
$$

190 where $\mathrm{d} m / \mathrm{d} t$ is the mass in weight percent at time $t, T_{\mathrm{p}}$ is the particle 191 temperature, $V M$ is the maximum volatile matter in weight percent 192 that can be lost, $V_{\mathrm{g}}$ is the total amount of volatile gases in weight 193 percent that have left the particle, and $k(T)$ is the rate constant 194 expressed by the Arrhenius equation (eq 4)

195

$$
k_{\mathrm{V}}=A_{\mathrm{V}} T_{\mathrm{p}}^{\gamma} \exp \left(\frac{-E_{\mathrm{V}}}{R T_{\mathrm{p}}}\right)
$$

where $R$ is the ideal gas constant $\left(\mathrm{J} \mathrm{K}^{-1} \mathrm{~mol}^{-1}\right), A_{\mathrm{V}}$ is the pre- 196 exponential factor $\left(\mathrm{s}^{-1}\right), E_{\mathrm{V}}$ is the activation energy $(\mathrm{J} / \mathrm{mol})$, and $\gamma$ is 197 the temperature power coefficient.

Char combustion is modeled using a single reaction as well. ${ }^{31}$ The 199 reaction rate is defined as a function of the temperature, concentration 200 of the oxidizer, and degree of conversion though eq 5

$$
\frac{\mathrm{d} X}{\mathrm{~d} t}=k\left(T_{\mathrm{p}}\right) P_{\mathrm{O}_{2}}{ }^{n}(1-X)
$$

where $X$ is the biomass conversion, $P_{\mathrm{O}_{2}}$ is the partial pressure of the 203 oxidizer, and $n$ is the reaction order. The rate constant is also 204 expressed by a variation of the Arrhenius equation 205

$$
k_{\mathrm{C}}=A_{\mathrm{C}} \exp \left(\frac{-E_{\mathrm{C}}}{R T_{\mathrm{p}}}\right)
$$

In the case of combustion, the total mass loss is defined as the 207 summation of the devolatilization and the char combustion rate. 208

The kinetic parameters considered for fitting are $A_{\mathrm{V}}, \gamma, E_{\mathrm{C}}, A_{\mathrm{C}}, E_{\mathrm{V}}, 209$ and $n$. The reaction order $n$ was limited to the typical values for the 210 temperatures used in thermogravimetric analysis (i.e., from 0.5 to 1 ), ${ }^{32} 211$ and the temperature power coefficients were limited to the -10 to 10212 universe values. ${ }^{30}$ The evaluation function to be minimized by the 213 genetic algorithm followed a similar form as that used in the work of 214 Ferreiro et al. ${ }^{30}$ Here, the global error is defined as a combination of 215 (i) the error between the predicted and experimental mass loss curve 216 (TG) and (ii) the characteristic temperature of the maximum peaks of 217 the rate curve (DTG). In the case of combustion, two peaks are 218 considered: the maximum devolatilization peak and the maximum char 219 combustion peak.

As an example of the qualitative interpretation of the biomass 221 pyrolysis and combustion profiles, Figure 3 shows the experimental $222 \mathrm{f} 3$ and model prediction results for the demineralized biomass. The 223 pyrolysis and combustion models capture, in general, well the overall 224 behavior of the biomass devolatilization and char oxidation processes. 225
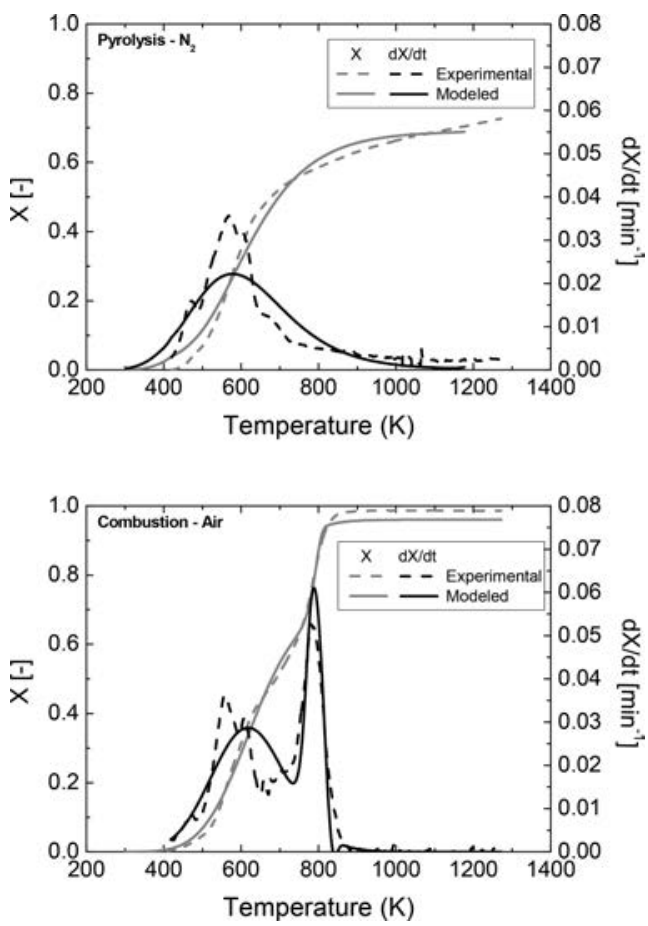

Figure 3. Typical pyrolysis and combustion profiles of the demineralized grape pomace. Experimental data, dashed lines; model data, continuous lines. 


\section{RESULTS AND DISCUSSION}

226 3.1. Influence of Potassium and Calcium on the 227 Biomass Pyrolysis and Combustion Processes. To analyze 228 the reactivity of the biomass samples, the peak temperature $229(P T)$, where the conversion rate is maximum, ${ }^{33}$ is used. 230 Considering a reference $P T$, it is found that the lower the peak 231 temperature, the higher the reactivity of a fuel.

232 Figure 4 shows the conversion, $X$, and the conversion rate, $233 \mathrm{~d} X / \mathrm{d} t$, versus the temperature of the raw grape pomace and the
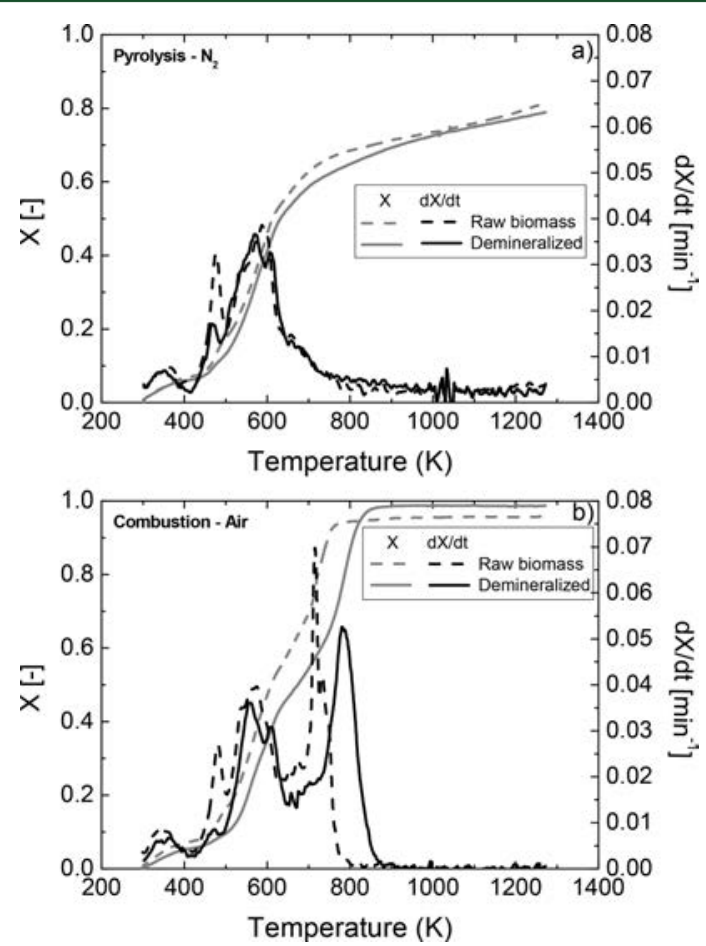

Figure 4. (a) Pyrolysis in $\mathrm{N}_{2}$ and (b) combustion with air of raw and demineralized grape pomace up to $1275 \mathrm{~K}$ at $10 \mathrm{~K} / \mathrm{min}$ in the TGA.

234 demineralized grape pomace during the pyrolysis and 235 combustion processes.

236 The pyrolysis conversion profile of both biomass samples 237 (Figure 4a) is characterized by an initial rapid decomposition, 238 in the $425-650 \mathrm{~K}$ temperature interval, followed by a slower 239 process up to a biomass conversion of about 0.8 at $1275 \mathrm{~K}$. This 240 process is related to the release of the volatile matter in 241 biomass. The more rapid initial conversion profile is associated 242 with the subsequent decomposition of hemicellulose and 243 cellulose, and the latter conversion profile is attributed to the 244 slow degradation of lignin. ${ }^{34}$ The combustion conversion 245 profile (Figure $4 \mathrm{~b}$ ) shows two rapid conversion stages separated 246 by a gradual transition stage. As in the pyrolysis case, the first 247 stage is related to the volatile matter release, while the second 248 stage is related to a rapid char conversion enhanced by the 249 oxygen in air. For both the raw and demineralized grape 250 pomace, the main volatile matter release stage is finished at 251 around $675 \mathrm{~K}$. However, the char conversion stage is finished at $252800 \mathrm{~K}$ for the raw biomass and $875 \mathrm{~K}$ for the demineralized 253 biomass, pointing to a catalytic effect of metals during the char 254 oxidation process. The demineralized biomass was fully 255 consumed during its interaction with air ( 0.99 conversion), 256 whereas the maximum conversion for the raw biomass is 0.96 . 257 This difference is attributed to the ash content of the raw grape pomace (cf. Table 1) and supports the effectiveness of the 258 demineralization process.

Figure 4 also shows the pyrolysis and combustion rates. After 260 the first peak at $350 \mathrm{~K}$ that corresponds to the water release, for 261 both the pyrolysis and combustion processes, the grape pomace 262 devolatilization shows three distinct peaks. These peaks are 263 generally associated with the release of the three main biomass 264 components: hemicellulose (at 498-598 K), cellulose (at 598- 265 $648 \mathrm{~K}$ ), and lignin (at 523-773 K). ${ }^{5}$ The pyrolysis curve 266 corresponding to the demineralized biomass shows the three 267 peaks at the same temperature as in the case of the raw 268 biomass, pointing to a marginal effect of the ash constituents of 269 grape pomace on the characteristic temperatures of the volatile 270 matter release. However, the magnitude of the peaks is slightly 271 affected by the biomass demineralization treatment. The 272 magnitude of the first peak, associated with hemicellulose, is 273 the most affected. It substantially decreases when the biomass is 274 demineralized. Previous studies ${ }^{35,36}$ indicate that the deminer- 275 alization processes, such as water or mild acid washing, can 276 separate and sharpen the peaks of the rate curves. In the 277 present work, the hemicellulose peak from the demineralized 278 biomass is significantly decreased, up to almost disappearance, 279 presumably as a result of its chemical degradation during the 280 acid demineralization. ${ }^{37}$

281

The char oxidation stage exhibits one single peak stronger 282 than the devolatilization general main peak. The mineral 283 content of biomass influences the magnitude and temperature 284 of the char oxidation peak; it is decreased and shifted to higher 285 temperatures when the biomass was demineralized, reinforcing 286 the catalytic effect of metals on char combustion.

287

To establish how the reactivity of the biomass is affected by 288 the presence and concentration of $\mathrm{K}$ and $\mathrm{Ca}$, the pyrolysis and 289 combustion rates from the demineralized biomass are taken as a 290 reference. Therefore, Figures 5 and 6 show the rate of mass loss $291 \mathrm{fsf6}$ for the demineralized grape pomace and all of the K- and Ca- 292 doped biomass samples considered in this work during their 293 pyrolysis and combustion, respectively. The conversion profiles 294 used to draw data shown in Figures 5 and 6 are included as 295 Figures $1 \mathrm{~S}$ and $2 \mathrm{~S}$ of the Supporting Information, respectively. 296

The general biomass pyrolysis profile (Figure 5) is neither 297 influenced by the $\mathrm{K}$ nor Ca content. Independent of the $\mathrm{K}$ and 298 Ca contents, the volatile matter release stage takes place in the 299 425-650 K temperature interval, with the main devolatilization 300 peak within this range. In the case of the Ca-doped biomass 301 samples, especially for the samples with 3 and 6 wt \% Ca, the 302 $\mathrm{d} X / \mathrm{d} t$ profile shows two distinct peaks, at $\sim 750$ and $\sim 925 \mathrm{~K}, 303$ respectively, that can be associated with the Ca transformations 304 at a high temperature. The reactant used in the present work to 305 dope the demineralized biomass with $\mathrm{Ca}$ is calcium oxalate 306 monohydrate $\left(\mathrm{CaC}_{2} \mathrm{O}_{4} \cdot \mathrm{H}_{2} \mathrm{O}\right)$. Its thermal decomposition 307 involves dehydration, decomposition of calcium oxalate to 308 calcium carbonate $\left(\mathrm{CaCO}_{3}\right)$, and further decomposition of 309 calcium carbonate to calcium oxide $(\mathrm{CaO}){ }^{38}$ Therefore, the 310 characteristic peaks obtained would correspond to the 311 decomposition of $\mathrm{CaC}_{2} \mathrm{O}_{4}$ to $\mathrm{CaCO}_{3}$ and the subsequent 312 formation of $\mathrm{CaO}$. It is also interesting to note that the 313 magnitude of the $\mathrm{CaC}_{2} \mathrm{O}_{4}$ and $\mathrm{CaCO}_{3}$ decomposition peaks 314 decreases as the amount of $\mathrm{Ca}$ used during the impregnation of 315 the biomass decreases. As indicated in the Introduction, during 316 a thermochemical process, $\mathrm{Ca}$ is released as small micrometer- 317 sized $\mathrm{CaO}$ particles, which would support these observations. 318 

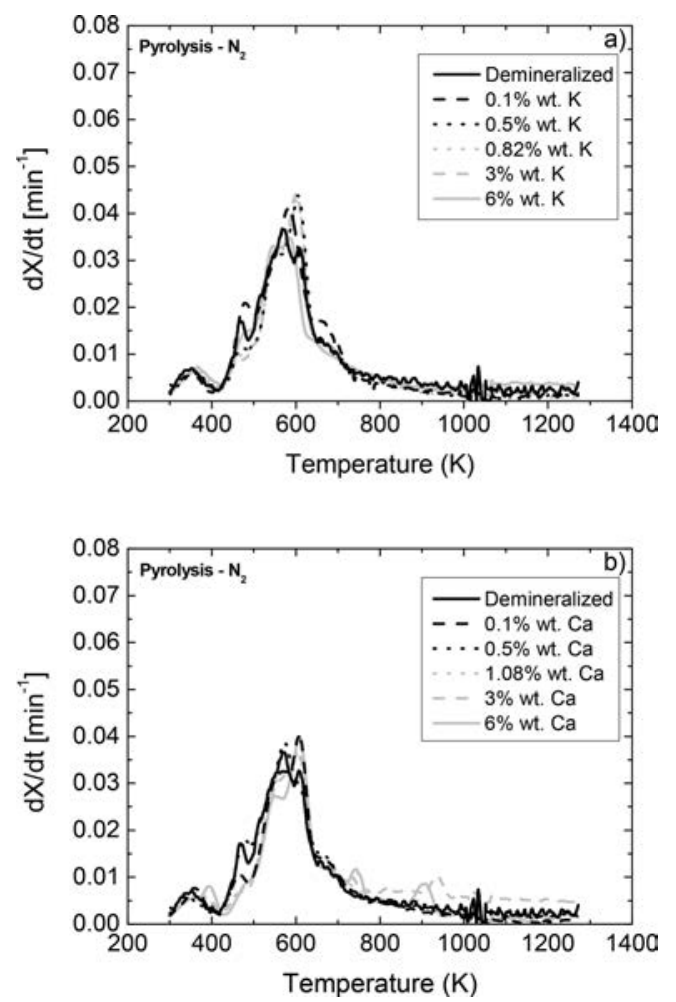

Figure 5. Pyrolysis profiles of demineralized grape pomace and grape pomace doped with the different concentrations of (a) $\mathrm{K}$ and (b) Ca.
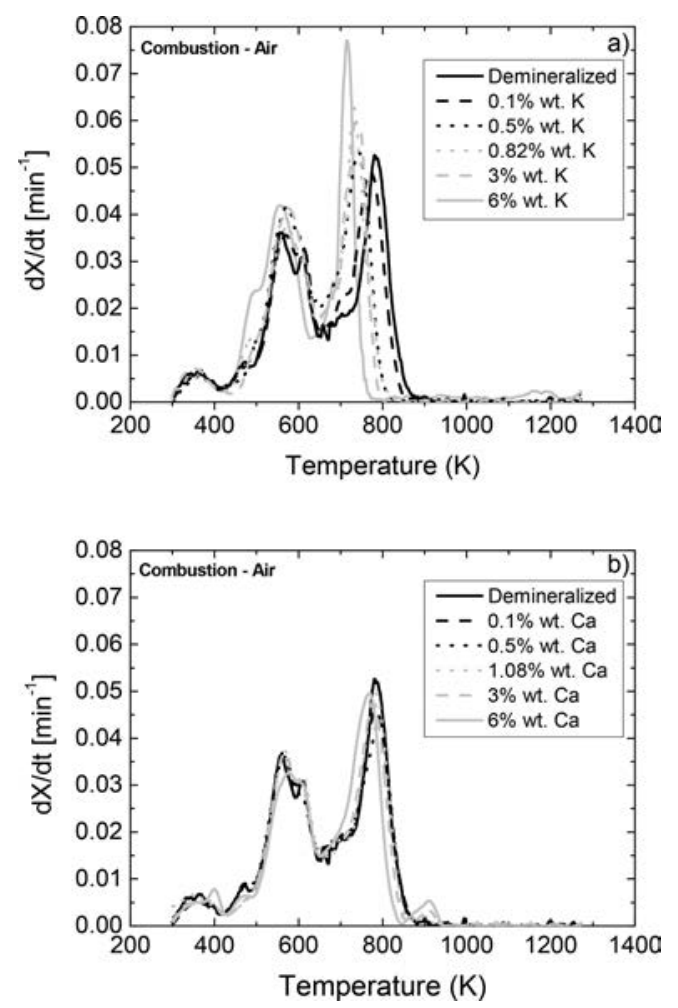

Figure 6. Combustion profiles of demineralized grape pomace and grape pomace doped with different concentrations of (a) $\mathrm{K}$ and (b) Ca.

319 For the K-doped biomass samples, the pyrolysis $\mathrm{d} X / \mathrm{d} t$ 320 profile does not show any additional peak associated with the 321 presence of $\mathrm{K}$ or its concentration.
In the case of biomass combustion (Figure 6), the main 322 devolatilization peak is not significantly affected by the $\mathrm{K}$ and 323 $\mathrm{Ca}$ contents of the biomass. However, $\mathrm{K}$ and Ca play a different 324 role on the char oxidation process. In general, the char 325 oxidation is promoted with an increasing $\mathrm{K}$ content, whereas 326 $\mathrm{Ca}$ does not significantly influence this process. The char 327 oxidation peak temperature is progressively shifted to lower 328 temperatures, and its intensity increased as the $\mathrm{K}$ content of 329 biomass is increased. For example, the peak temperature is 330 shifted from 786 to $714 \mathrm{~K}$ with increasing the $\mathrm{K}$ content from 331 demineralized biomass to $6 \mathrm{wt} \% \mathrm{~K}$. These results are in line 332 with the observations of Fuentes et al. ${ }^{27}$ in relation to the 333 catalytic effect of $\mathrm{K}$ on the char oxidation stage of biomass 334 conversion and the lower activity of Ca. Moreover, these 335 authors did not observed any effect of $\mathrm{Ca}$ on the volatile release 336 stage. For the sample with $6 \mathrm{wt} \% \mathrm{~K}$, it is interesting to note a 337 small characteristic peak at $\sim 1180 \mathrm{~K}$, which can be related to 338 the decomposition of potassium carbonate $\left(\mathrm{K}_{2} \mathrm{CO}_{3}\right)$ to 339 potassium oxide $\left(\mathrm{K}_{2} \mathrm{O}\right) ;{ }^{12}$ the thermal conversion of potassium 340 oxalate monohydrate (reactant used to dope the biomass with 341 $\mathrm{K}$ ) involves dehydration and its decomposition to potassium 342 carbonate $\left(\mathrm{K}_{2} \mathrm{CO}_{3}\right) \cdot{ }^{38}$ Table 2 summarized the characteristic 343 t2 temperatures of the volatile matter release and char oxidation 344 regions.

345

Considering the results of the raw biomass sample and the 346 biomass impregnated with similar amounts of $\mathrm{K}$ and $\mathrm{Ca}$ (i.e., 347 0.82 wt $\% \mathrm{~K}$ and 1.08 wt \% Ca, respectively), it can be stated 348 that neither $\mathrm{K}$ nor $\mathrm{Ca}$ is individually responsible for the catalytic 349 effect of the mineral constituents of raw biomass, which points 350 to a synergistic and/or cumulative effect of those minerals that 351 actively catalyze the char oxidation stage of biomass 352 combustion.

3.2. Influence of Potassium and Calcium on the 354 Biomass Ignition Temperature. The minimum ignition 355 temperature from TGA results can be determined by four 356 different graphical methods: (i) the TG-DTG tangent 357 method, ${ }^{39}$ where the ignition temperature is defined by the 358 intersection between the tangent to the TG curve at the main 359 DTG peak and the horizontal line tangent to the TG curve 360 after the water release peak (Figure 7a), (ii) the TG divergence $361 \mathrm{f} 7$ method, $^{40}$ where the ignition temperature is defined by the 362 separation of the pyrolysis and combustion TG curves (Figure 363 7b), (iii) the DTG decrease method, ${ }^{41}$ where the ignition 364 temperature is defined from the sudden decrease in the DTG 365 curve after the water release stage (Figure 7c), and (iv) the 366 DTG threshold method, ${ }^{42,43}$ where the ignition temperature is 367 determined by the $1 \% / \mathrm{min}$ weight loss rate decrease after the 368 water release stage (Figure $7 \mathrm{~d}$ ).

The characteristic ignition temperature depends strongly 370 upon the specific graphical method used (see results shown in 371 Figure 7), but results based on a consistent definition of the 372 methodology and considering a reference case can be used to 373 quantitatively compare the combustion behavior of biomass 374 doped with different concentrations of $\mathrm{K}$ and $\mathrm{Ca}$. 375

As discussed in section 3.1, the demineralization process 376 affects the magnitude of the first peak after the water release 377 stage, the hemicellulose peak. In the DTG threshold method, 378 the ignition temperature is determined from the behavior of 379 this first peak (see Figure 7d), and consequently, the results 380 obtained with the biomass samples examined in the present 381 work would not be reliable. Therefore, the DTG threshold 382 method for the determination of the ignition temperature is not 383 considered in this study. 
Table 2. Characteristic Temperatures (K) of the Devolatilization Region of Pyrolysis and the Volatile Matter Release and Char Oxidation Regions of Combustion of the Raw and Demineralized Grape Pomace and Doped with the Different Concentrations of $\mathrm{K}$ and $\mathrm{Ca}^{a}$

\begin{tabular}{|c|c|c|c|c|c|c|c|c|c|}
\hline \multirow[b]{3}{*}{ biomass sample } & & & & \multicolumn{6}{|c|}{ combustion } \\
\hline & \multicolumn{3}{|c|}{ pyrolysis } & \multicolumn{3}{|c|}{ devolatilization } & \multicolumn{3}{|c|}{ char oxidation } \\
\hline & $T_{\mathrm{i}}$ & $P T_{\mathrm{dev}}$ & $T_{\mathrm{f}}$ & $T_{\mathrm{i}}$ & $P T_{\text {vol }}$ & $T_{\mathrm{f}}$ & $T_{\mathrm{i}}$ & $P T_{\text {char }}$ & $T_{\mathrm{f}}$ \\
\hline raw biomass & 412 & 586 & 626 & 420 & 569 & 633 & 634 & 722 & 775 \\
\hline demineralized biomass & 420 & 576 & 646 & 418 & 565 & 656 & 657 & 786 & 875 \\
\hline 0.1 wt $\% \mathrm{~K}$ & 400 & 583 & 637 & 420 & 572 & 652 & 653 & 772 & 853 \\
\hline $0.5 \mathrm{wt} \% \mathrm{~K}$ & 420 & 607 & 640 & 418 & 572 & 647 & 648 & 743 & 821 \\
\hline $0.82 \mathrm{wt} \% \mathrm{~K}$ & 420 & 607 & 637 & 420 & 572 & 641 & 642 & 736 & 825 \\
\hline 3 wt \% K & 422 & 600 & 635 & 432 & 575 & 647 & 648 & 736 & 800 \\
\hline 6 wt $\% \mathrm{~K}$ & 420 & 586 & 626 & 418 & 558 & 631 & 632 & 714 & 775 \\
\hline 0.1 wt $\% \mathrm{Ca}$ & 420 & 607 & 643 & 430 & 565 & 645 & 646 & 786 & 878 \\
\hline 0.5 wt \% Ca & 415 & 572 & 641 & 424 & 569 & 652 & 653 & 793 & 878 \\
\hline $1.08 \mathrm{wt} \% \mathrm{Ca}$ & 420 & 604 & 644 & 424 & 568 & 670 & 671 & 786 & 868 \\
\hline 3 wt \% Ca & 424 & 607 & 640 & 428 & 569 & 649 & 650 & 779 & 860 \\
\hline 6 wt $\% \mathrm{Ca}$ & 426 & 608 & 646 & 430 & 579 & 654 & 655 & 768 & 843 \\
\hline
\end{tabular}
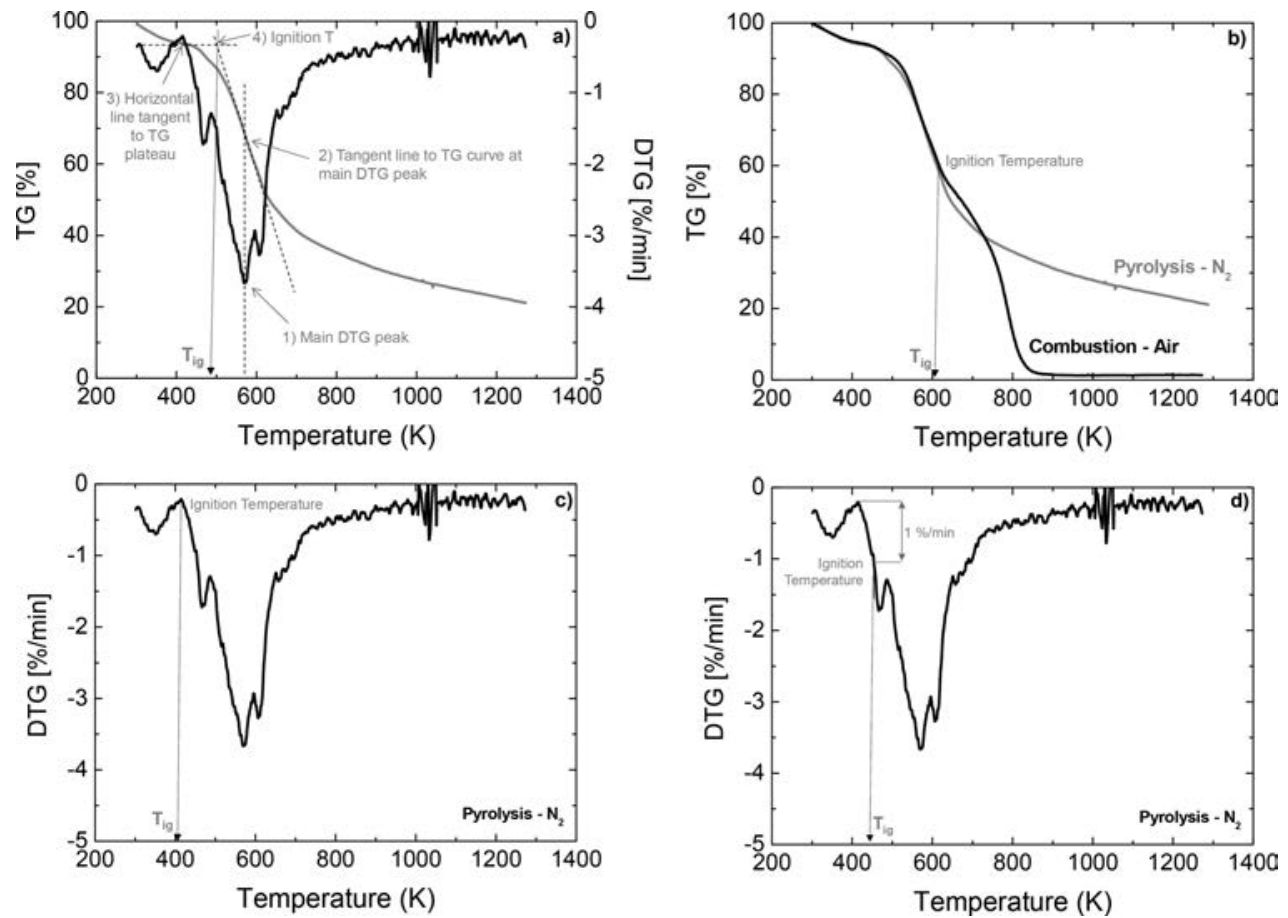

Figure 7. Graphical depiction of the (a) TG-DTG tangent method, (b) TG divergence method, (c) DTG decrease method, and (d) DTG threshold method used for the determination of the ignition temperature. Reference biomass is demineralized grape pomace.

385 Figure 8 shows the ignition temperature of the raw and 386 demineralized grape pomace and doped with $\mathrm{K}$ and $\mathrm{Ca}$. 387 Independent of the method used for the determination of the $388 T_{\text {ig }}$, data, the figure indicates that neither the demineralization 389 process nor the presence of $\mathrm{K}$ and $\mathrm{Ca}$ (from low to high 390 concentrations) significantly modifies the minimum ignition 391 temperature of the biomass. For all biomass samples analyzed, 392 the characteristic ignition temperatures $\left(T_{\mathrm{ig}}\right)$ obtained with the 393 DTG decrease method are in the order of $425 \mathrm{~K}$, with the TG394 DTG tangent method in the order of $515 \mathrm{~K}$, and with the TG 395 divergence method, the ignition temperatures increase further 396 to values around $645 \mathrm{~K}$.

397 3.3. Influence of Potassium and Calcium on the $\mathrm{t} 3$ parameters (activation energy and pre-exponential factor) 399 obtained for the devolatilization process during the biomass 400 pyrolysis and the volatile matter release and char oxidation 401 processes during the biomass combustion. The values reported 402 in Table 3 are the averaged values from three runs for each 403 biomass and condition. The variation of the coefficients 404 reported for the activation energy values were in all cases 405 lower than $10 \%$ for the pyrolysis process and lower than 2 and 406 $2.2 \%$ for the devolatilization and char oxidation processes, 407 respectively, during combustion.

408

For all of the samples analyzed, the pre-exponential factor 409 values for the pyrolysis and devolatilization processes $\left(A_{\mathrm{V}}\right)$ were 410 in the order of $10^{21}$ and the pre-exponential factor values for 411 the char oxidation process during combustion $\left(A_{\mathrm{C}}\right)$ were in the 412 

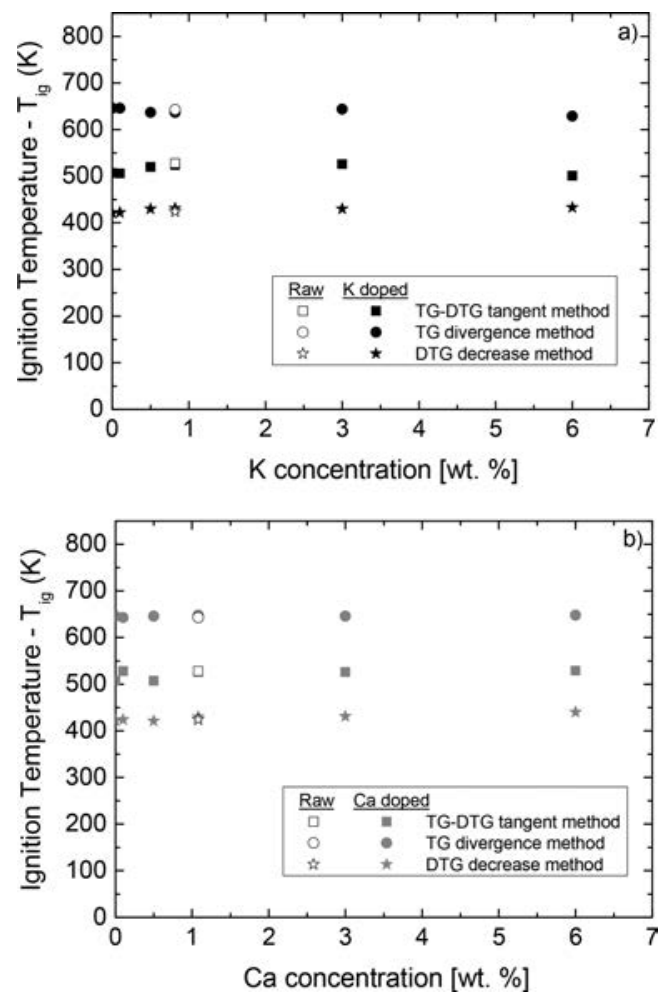

Figure 8. Characteristic ignition temperatures of raw and demineralized grape pomace and doped with different concentrations of (a) $\mathrm{K}$ and (b) Ca.

413 order of $10^{18}$. The temperature power coefficient $(\gamma)$ laid within 414 the -7.5 to -6.5 interval, independent of the process 415 considered. In this work, $\gamma$ is considered as an additional 416 parameter for the fitting procedure; consequently, no further 417 information is extracted from these values.

418 The pyrolysis process shows activation energies between 45 419 and $54 \mathrm{~kJ} / \mathrm{mol}$, and the devolatilization and char oxidation 420 processes show activation energies between 58 and $68 \mathrm{~kJ} / \mathrm{mol}$ 421 and between 319 and $346 \mathrm{~kJ} / \mathrm{mol}$, respectively. The activation 422 energy for the char oxidation is, in general, 5 times higher than 423 that corresponding to the volatile matter release, which is in 424 agreement with the different temperature windows for the 425 occurrence of each of these stages (cf. Table 3). It is also interesting to note that the activation energy of the volatile 426 matter release process during the biomass combustion is quite 427 similar to that corresponding to the biomass pyrolysis, which is 428 in agreement with the similarity of the characteristic temper- 429 atures of both processes.

Figure 9 summarizes the individual activation energy of each $431 \mathrm{f} 9$ biomass sample and process. In this figure, the data points with 432
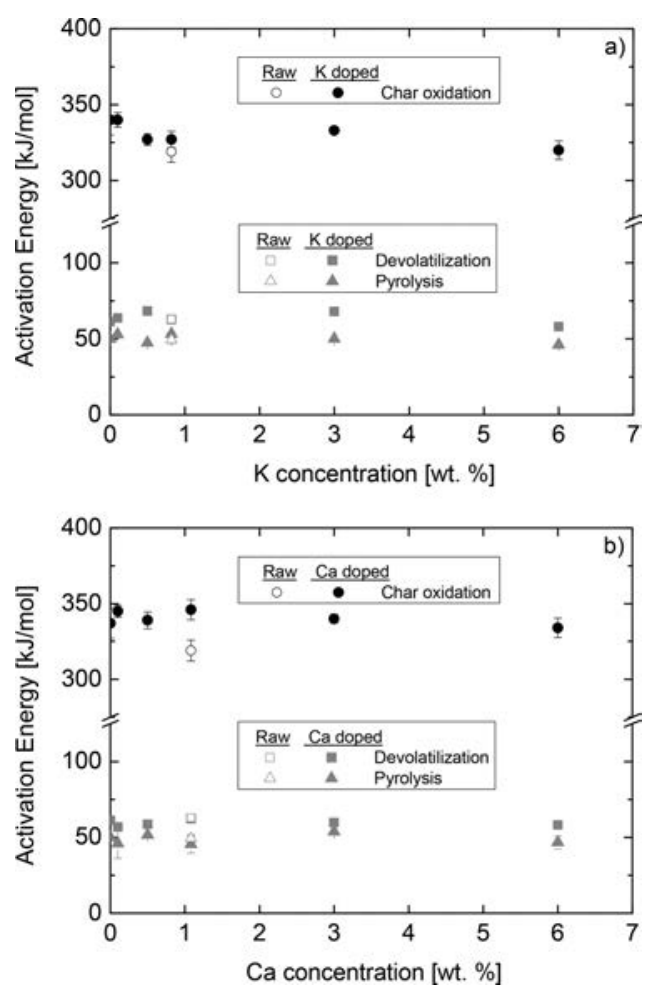

Figure 9. Activation energies of the pyrolysis and oxidation of raw and demineralized grape pomace and doped with different concentrations of (a) K and (b) Ca.

zero concentration correspond to the demineralized biomass 433 sample, and the hollow symbols correspond to the raw biomass 434 sample. The activation energy of the devolatilization process 435 $\left(E_{\mathrm{V}}\right)$ during both the pyrolysis and combustion of biomass is 436 almost insensitive to the variation of the $\mathrm{K}$ and $\mathrm{Ca} 437$

Table 3. Kinetic Parameters of Pyrolysis and Combustion of Raw Grape Pomace, Demineralized Grape Pomace, and Doped with Different Concentrations of $\mathrm{K}$ and $\mathrm{Ca}$

\begin{tabular}{|c|c|c|c|c|c|c|}
\hline \multirow[b]{3}{*}{ biomass sample } & & & \multicolumn{4}{|c|}{ combustion } \\
\hline & \multicolumn{2}{|c|}{ pyrolysis } & \multicolumn{2}{|c|}{ devolatilization } & \multicolumn{2}{|c|}{ char oxidation } \\
\hline & $E_{\mathrm{V}}(\mathrm{kJ} / \mathrm{mol})$ & $A_{\mathrm{V}}\left(\mathrm{s}^{-1}\right)$ & $E_{\mathrm{V}}(\mathrm{kJ} / \mathrm{mol})$ & $A_{\mathrm{V}}\left(\mathrm{s}^{-1}\right)$ & $E_{\mathrm{C}}(\mathrm{kJ} / \mathrm{mol})$ & $A_{\mathrm{C}}\left(\mathrm{atm}^{-1} \mathrm{~s}^{-1}\right)$ \\
\hline raw biomass & 49.4 & $3.79 \times 10^{21}$ & 63.0 & $2.18 \times 10^{21}$ & 319 & $4.84 \times 10^{18}$ \\
\hline demineralized biomass & 50.0 & $7.91 \times 10^{21}$ & 61.5 & $7.40 \times 10^{21}$ & 340 & $1.92 \times 10^{18}$ \\
\hline 0.1 wt $\% \mathrm{~K}$ & 53.0 & $2.10 \times 10^{21}$ & 63.5 & $4.60 \times 10^{21}$ & 340 & $4.56 \times 10^{18}$ \\
\hline 0.5 wt $\% \mathrm{~K}$ & 47.4 & $3.30 \times 10^{21}$ & 68.0 & $5.38 \times 10^{21}$ & 327 & $5.39 \times 10^{18}$ \\
\hline 0.82 wt \% $\mathrm{K}$ & 53.2 & $3.09 \times 10^{21}$ & 63.0 & $7.66 \times 10^{21}$ & 327 & $5.54 \times 10^{18}$ \\
\hline 3 wt \% K & 50.2 & $8.84 \times 10^{21}$ & 67.8 & $3.93 \times 10^{21}$ & 333 & $7.85 \times 10^{18}$ \\
\hline 6 wt $\% \mathrm{~K}$ & 46.2 & $5.50 \times 10^{21}$ & 58.1 & $6.37 \times 10^{21}$ & 320 & $4.33 \times 10^{18}$ \\
\hline 0.1 wt $\% \mathrm{Ca}$ & 46.0 & $4.55 \times 10^{21}$ & 56.8 & $8.18 \times 10^{21}$ & 345 & $4.66 \times 10^{18}$ \\
\hline 0.5 wt \% Ca & 51.7 & $7.71 \times 10^{21}$ & 58.7 & $3.42 \times 10^{21}$ & 339 & $1.45 \times 10^{18}$ \\
\hline 1.08 wt $\% \mathrm{Ca}$ & 45.5 & $3.77 \times 10^{21}$ & 62.3 & $7.21 \times 10^{21}$ & 346 & $7.12 \times 10^{18}$ \\
\hline 3 wt \% Ca & 53.8 & $5.84 \times 10^{21}$ & 59.8 & $4.63 \times 10^{21}$ & 340 & $2.31 \times 10^{18}$ \\
\hline 6 wt $\% \mathrm{Ca}$ & 46.7 & $3.83 \times 10^{21}$ & 58.2 & $5.33 \times 10^{21}$ & 334 & $3.82 \times 10^{18}$ \\
\hline
\end{tabular}


438 concentrations of biomass, but the activation energy of the char 439 oxidation process $\left(E_{\mathrm{C}}\right)$ during the combustion of biomass is 440 somewhat sensitive to the mineral content of biomass. In this 441 way, the activation energy of the char oxidation stage from the 442 combustion of the demineralized biomass sample is $6.6 \%$ higher 443 than the $E_{C}$ value of the raw sample of grape pomace.

444 In the case of $\mathrm{K}$ (Figure 9a), the activation energy of the char 445 oxidation process $\left(E_{\mathrm{C}}\right)$ decreases with the increase of the $\mathrm{K}$ 446 concentration until the 0.5 wt $\% \mathrm{~K}$ sample and continues 447 slightly decreasing further up to 6 wt $\% \mathrm{~K}$, where the $E_{\mathrm{C}}$ value is 448 similar to that corresponding to the raw grape pomace sample. 449 As for the devolatilization process, Ca (Figure 9b) has a 450 marginal effect on the activation energy of the char oxidation 451 process. The $E_{\mathrm{C}}$ value for the biomass samples with different $\mathrm{Ca}$ 452 concentrations is very close to the $E_{C}$ value of the 453 demineralized biomass.

\section{CONCLUSION}

454 The individual role of the presence and concentration of $\mathrm{K}$ and $455 \mathrm{Ca}$ in the combustion characteristics of grape pomace has been 456 analyzed. The grape pomace was demineralized and, sub457 sequently, doped with $\mathrm{K}$ and $\mathrm{Ca}$ to obtain doped samples that 458 covered a wide and realistic concentration range of both 459 minerals in different biomass fuels. Specifically, this work 460 includes the analysis of the pyrolysis and oxidation processes in 461 a TGA of raw and demineralized grape pomace and 462 demineralized biomass doped with $0.1,0.5,0.82,3$, and $6 \mathrm{wt}$ $463 \% \mathrm{~K}$ and $0.1,0.5,1.08,3$, and 6 wt \% Ca.

464 In general, neither the ignition temperature nor the 465 devolatilization process of biomass is significantly affected by 466 the presence of $\mathrm{K}$ and $\mathrm{Ca}$ contents lower than $6 \mathrm{wt} \%$. The char 467 oxidation was promoted by the presence of $\mathrm{K}$, with a more 468 noticeable effect as the $\mathrm{K}$ concentration in the biomass was 469 increased. In this case, the char oxidation profile of the biomass 470 doped with 6 wt \% K was shifted $72 \mathrm{~K}$ to lower temperatures 471 compared to the demineralized biomass.

472 The activation energies for the volatile matter release during 473 the pyrolysis and oxidation of biomass were in the intervals of 474 45-54 and 58-69 kJ/mol, respectively, while for char 475 oxidation, it was in the interval of $318-346 \mathrm{~kJ} / \mathrm{mol}$. The 476 impact of the mineral content of biomass is more significant on 477 the char oxidation process of biomass combustion than on the 478 pyrolysis and devolatilization processes. Neither high concen479 trations of $\mathrm{Ca}$ and $\mathrm{K}$ (up to 6 wt \% of each individual mineral) 480 nor the minerals present in the raw grape pomace influence the 481 activation energy of the pyrolysis and devolatilization process of 482 biomass combustion. The minerals present in the raw grape 483 pomace and $\mathrm{K}$ individually show a catalytic effect on the 484 activation energy of the char oxidation process. This effect is 485 promoted by increased $\mathrm{K}$ concentrations. On the contrary, 486 under the conditions of the present work, $\mathrm{Ca}$ behaves as an 487 inert.

\section{ASSOCIATED CONTENT}

\section{S Supporting Information}

490 The Supporting Information is available free of charge on the 491 ACS Publications website at DOI: 10.1021/acs.energy492 fuels.7b02161.

493 Pyrolysis in $\mathrm{N}_{2}$ of demineralized grape pomace and grape 494 pomace doped with different concentrations of (a) K and 495 (b) Ca (Figure 1S) and combustion with air of 496 demineralized grape pomace and grape pomace doped with different concentrations of (a) K and (b) Ca (Figure 497 2S) (PDF)

AUTHOR INFORMATION

Corresponding Author

500

*E-mail: mabian@unizar.es.

ORCID $\odot$

M. Abián: 0000-0001-7559-9669

M. U. Alzueta: 0000-0003-4679-5761

Notes

The authors declare no competing financial interest.

\section{ACKNOWLEDGMENTS}

507

The work was funded by MINECO and FEDER (Project 508 CTQ2015-65226) and Fundação para a Ciência e a Tecnologia 509 (FCT), through IDMEC, under LAETA Pest-OE/EME/ 510 LA0022 and PTDC/EMS-ENE/5710/2014. M. Abián ac- 511 knowledges MINECO and Instituto de Carboquímica (ICB- 512 CSIC) for the postdoctoral grant awarded (FPDI-2013-16172) 513 and Fundaciones Ibercaja y CAI (Program Ibercaja-CAI for 514 research stays) and COST Action CM1404 (EU) for financial 515 support (reference ECOST-STSM-CM1404-010716-079613). 516

\section{REFERENCES}

(1) Niu, Y.; Tan, H.; Hui, S. Prog. Energy Combust. Sci. 2016, 52, 1- 518 61.

(2) Glarborg, P. Proc. Combust. Inst. 2007, 31, 77-98.

(3) Di Blasi, C. Prog. Energy Combust. Sci. 2008, 34, 47-90.

(4) Tortosa-Masiá, A. A.; Buhre, B. J. P.; Gupta, R. P.; Wall, T. F. Fuel 522 Process. Technol. 2007, 88, 1071-1081.

(5) Nunes, L. J. R.; Matias, J. C. O.; Catalão, J. P. S. Renewable 52 Sustainable Energy Rev. 2016, 53, 235-242.

(6) Vassilev, S. V; Baxter, D.; Andersen, L. K, Vassileva, C. G. Fuel s2 2010, 89, 913-933.

(7) Niu, Y.; Zhu, Y.; Tan, H.; Hui, S.; Jing, Z.; Xu, W. Fuel Process. 528 Technol. 2014, 128, 499-508.

(8) Lindstrom, E.; Sandstrom, M.; Bostrom, D.; Ohman, M. Energy 530 Fuels 2007, 21, 710-717.

(9) Lindstrom, E.; Ohman, M.; Backman, R.; Bostrom, D. Energy 532 Fuels 2008, 22, 2216-2220.

(10) Jones, J. M. Darvell, L. I. Bridgeman, T. G.; Pourkashanian, M.; 534 Williams, A. Proc. Combust. Inst. 2007, 31, 1955-1963.

(11) Blomberg, T. Mater. Corros. 2011, 62, 635-641. 536

(12) Lehman, R. L.; Gentry, J. S.; Glumac, N. G. Thermochim. Acta 537 1998, 316, 1-9.

(13) Veksha, A.; Zaman, W.; Layzell, D. B.; Hill, J. M. Bioresour. 539 Technol. 2014, 171, 88-94. 540

(14) Raveendran, K.; Ganesh, A.; Khilar, K. C. Fuel 1995, 74, 1812- 541 1822.

(15) Nowakowski, D. J.; Jones, J. M. J. Anal. Appl. Pyrolysis 2008, 83, 543 $12-25$.

(16) Zhao, D.; Chen, K.; Yang, F.; Feng, G.; Sun, Y.; Dai, Y. Cellulose 545 2013, 20, 3205-3217.

(17) Zolin, A.; Jensen, A.; Jensen, P. A.; Frandsen, F.; Dam-Johansen, 547 K. Energy Fuels 2001, 15, 1110-1122.

(18) Fahmi, R.; Bridgwater, A. V; Darvell, L. I. Jones, J. M. Yates, 549 N.; Thain, S.; Donnison, I. S. Fuel 2007, 86, 1560-1569.

(19) Nowakowski, D. J.; Jones, J. M.; Brydson, R. M. D.; Ross, A. B. 551 Fuel 2007, 86, 2389-2402. 552

(20) Dall'Ora, M.; Jensen, P. A.; Jensen, A. D. Energy Fuels 2008, 22, 553 $2955-2962$.

(21) Boström, D.; Skoglund, N.; Grimm, A.; Boman, C.; Öhman, M.; 555 Broström, M.; Backman, R. Energy Fuels 2012, 26, 85-93. 556

(22) Pan, W.-P.; Richards, G. N. J. Anal. Appl. Pyrolysis 1989, 16, 557 117-126. 
559 (23) Aho, A.; DeMartini, N.; Pranovich, A.; Krogell, J.; Kumar, N.; 560 Eränen, K.; Holmbom, B.; Salmi, T.; Hupa, M.; Murzin, D. Yu. 561 Bioresour. Technol. 2013, 128, 22-29.

562 (24) Levendis, Y. A.; Nam, S. W.; Lowenberg, M.; Flagan, R. C.; 563 Gavalas, G. R. Energy Fuels 1989, 3, 28-37.

564 (25) Gopalakrishnan, R.; Fullwood, M. J.; Bartholomew, C. H. Energy 565 Fuels 1994, 8, 984-989.

566 (26) Gopalakrishnan, R.; Bartholomew, C. H. Energy Fuels 1996, 10, $567689-695$.

568 (27) Fuentes, M. E.; Nowakowski, F. J.; Kubacki, M. L.; Cove, J. M.; 569 Bridgeman, T. G.; Jones, J. M. J. Energy Inst. 2008, 81, 234-241.

570 (28) Perander, M.; DeMartini, N.; Brink, A.; Kramb, J.; Karlström, 571 O.; Hemming, J.; Moilanen, A.; Konttinen, J.; Hupa, M. Fuel 2015, 572 150, 464-472.

573 (29) White, J. E.; Catallo, W. J.; Legendre, B. L. J. Anal. Appl. Pyrolysis $5742011,91,1-33$.

575 (30) Ferreiro, A. I.; Rabaçal, M.; Costa, M. Energy Convers. Manage. 576 2016, 125, 290-300.

577 (31) Di Blasi, C. Prog. Energy Combust. Sci. 2009, 35, 121-140.

578 (32) Hurt, R. H.; Calo, J. M. Combust. Flame 2001, 125, 1138-1149.

579 (33) Cumming, J. W. Fuel 1984, 63, 1436-1440.

580 (34) Yang, H.; Yan, R.; Chen, H.; Lee, D. H.; Zheng, C. Fuel 2007, $58186,1781-1788$.

582 (35) Di Blasi, C.; Branca, C.; D’Errico, G. Thermochim. Acta 2000, 583 364, 133-142.

584 (36) Stenseng, M.; Jensen, A.; Dam-Johansen, K. J. Anal. Appl. 585 Pyrolysis 2001, 58-59, 765-780.

586 (37) Eom, I.-Y.; Kim, J.-Y.; Kim, T.-S.; Lee, S.-M.; Choi, D.; Choi, I.587 G.; Choi, J.-W. Bioresour. Technol. 2012, 104, 687-694.

588 (38) Dollimore, D. Thermochim. Acta 1987, 117, 331-363.

589 (39) Li, Q.; Zhao, C.; Chen, X.; Wu, W.; Li, Y. J. Anal. Appl. Pyrolysis $5902009,85,521-528$.

591 (40) Ma, B.-G.; Li, X.-G.; Xu, L.; Wang, K.; Wang, X.-G. Thermochim. 592 Acta 2006, 445, 19-22.

593 (41) Jones, J. M.; Lea-Langton, A. R.; Ma, L.; Pourkashanian, M.; 594 Williams, A. Pollutants Generated by the Combustion of Solid Biomass 595 Fuels; Springer: London, U.K., 2014; DOI: 10.1007/978-1-4471-64375961.

597 (42) Faúndez, J.; Arenillas, A.; Rubiera, F.; García, X.; Gordon, A. L.; 598 Pis, J. J. Fuel 2005, 84, 2172-2177.

599 (43) Moon, C.; Sung, Y.; Ahn, S.; Kim, T.; Choi, G.; Kim, D. Appl. 600 Therm. Eng. 2013, 54, 111-119. 